\title{
The September 26, 1997 Colfiorito, Italy, earthquakes: modeled coseismic surface displacement from SAR interferometry and GPS
}

\author{
S. Stramondo, ${ }^{1}$ M. Tesauro, ${ }^{2}$ P. Briole, ${ }^{3}$ E. Sansosti ${ }^{2}$ S. Salvi, ${ }^{1}$ R. Lanari, ${ }^{2}$ \\ M. Anzidei, ${ }^{1}$ P Baldi, ${ }^{4}$ G. Fornaro, ${ }^{2}$ A.Avallone, ${ }^{3}$ M.F. Buongiorno, ${ }^{1}$ G. \\ Franceschetti, ${ }^{2}$ E. Boschi, ${ }^{1}$
}

\begin{abstract}
The largest events of the 1997 UmbriaMarche seismic sequence were the two September 26 earthquakes of $\mathrm{Mw}=5.7$ (00:33 GMT) and $\mathrm{Mw}=6.0$ (09:40 GMT), which caused severe damage and ground cracks in a wide area around the epicenters. We created an ERS-SAR differential interferogram, where nine fringes are visible in and around the Colfiorito basin, corresponding to $25 \mathrm{~cm}$ of coseismic surface displacement. GPS data show a maximum horizontal displacement of $(14 \pm 1.8) \mathrm{cm}$ and a maximum subsidence of $(24 \pm 3) \mathrm{cm}$. We used these geodetic data and the seismological parameters to estimate geometry and slip distribution on the fault planes. Modeled fault depths and maximum slip amplitudes are $6.5 \mathrm{~km}$ and $47 \mathrm{~cm}$ for the first event and $7 \mathrm{~km}$ and $72 \mathrm{~cm}$ for the second one, in good agreement with those derived from the seismological data.
\end{abstract}

\section{Introduction}

Starting September 1997, a large area of the UmbriaMarche Apennines in Central Italy was struck by a strong seismic sequence. Activity began on September 3 with a $\mathrm{Mw}=4.5$ earthquake, then, on September 26 at 00:33 GMT, a Mw 5.7 earthquake occurred near the village of Colfiorito, followed at 09:40 GMT by a Mw 6.0 event [Amato et al., 1998]. The focal mechanisms for these events are all consistent with purely normal faulting with a NE-SW T axis (CMT solutions, [Ekström et al., 1998]). Most of the aftershocks were precisely located at depths ranging between 10 and 3 $\mathrm{km}$, suggesting SW-dipping fault planes [Amato et al., 1998]. Field observations [Cinti et al., 1998; Basili et al., 1998], allowed the identification of diffuse surface deformation features (mostly ground breaks with centi-

\footnotetext{
${ }^{1}$ Istituto Nazionale di Geofisica, Roma, Italy.

${ }^{2}$ IRECE-CNR, Napoli, Italy.

${ }^{3}$ Institute de Physique du Globe, Paris, France.

${ }^{4}$ Universitá di Bologna, Dipartimento di Fisica, Bologna, Italy.
}

Copyright 1999 by the American Geophysical Union.

Paper number 1999GL900141.

0094-8276/99/1999GL900141\$05.00 metric throw), along a $10 \mathrm{~km}$ wide belt coincident with the epicentral area. Even if the strain release during the Colfiorito shocks did not originate large tectonic surface ruptures, the seismic moment values (Table 2), the shallow depth of the seismicity and the aftershock distribution, all suggest that a diffuse zone of surface displacement had occurred. In this paper we present preliminary results of a GPS and SAR interferometry investigation for the two September 26, Colfiorito main shocks.

\section{The SAR interferometric fringes}

The Differential Interferometry technique, using Synthetic Aperture Radar data (DInSAR), has already been demonstrated to be an important tool for coseismic crustal displacement analysis [Massonnet et al., 1993]. We applied SAR interferometry to the epicentral area and obtained a good final interferogram using a high resolution DEM acquired from the Italian Istituto Geografico Militare (20 m spatial resolution, height accuracy of 10-20 m), to eliminate the effect of the topography.

We used a set of 30 ERS-1/ERS-2 images (from ascending and descending orbits) acquired from July 1993 to October 1997. To minimize the effects of errors in the DEM, we chose interferometric pairs with a high ambiguity height (i.e. the altitude variation producing a phase change of $2 \pi$ ). Our most coherent interferogram was obtained from a 35-day ERS-2 pair; the pre-seismic image was acquired on September 7, 1997 and the postseismic one on October 12. For these two images the ambiguity height is $79 \mathrm{~m}$, the orthogonal baseline 130 $\mathrm{m}$ and the parallel baseline $70 \mathrm{~m}$; according to the estimated accuracy of the DEM, the maximum expected error due to the topography is thus about $1 / 4$ of a fringe, (i.e. less than $7 \mathrm{~mm}$ ).

The differential interferogram shows (Figure 1) a pattern of concentric fringes with two clear relative minima in the areas of the Annifo and Colfiorito plains (zone of maximum damage). The general pattern elongation agrees with the strike of the mainshock fault planes as determined from the CMT solutions $\left(140^{\circ}-150^{\circ}\right.$, $[E k$ ström et al., 1998]). The fringe pattern also shows a marked asymmetry, with closer fringes (i.e. a higher displacement gradient) towards the NE; its extension is 


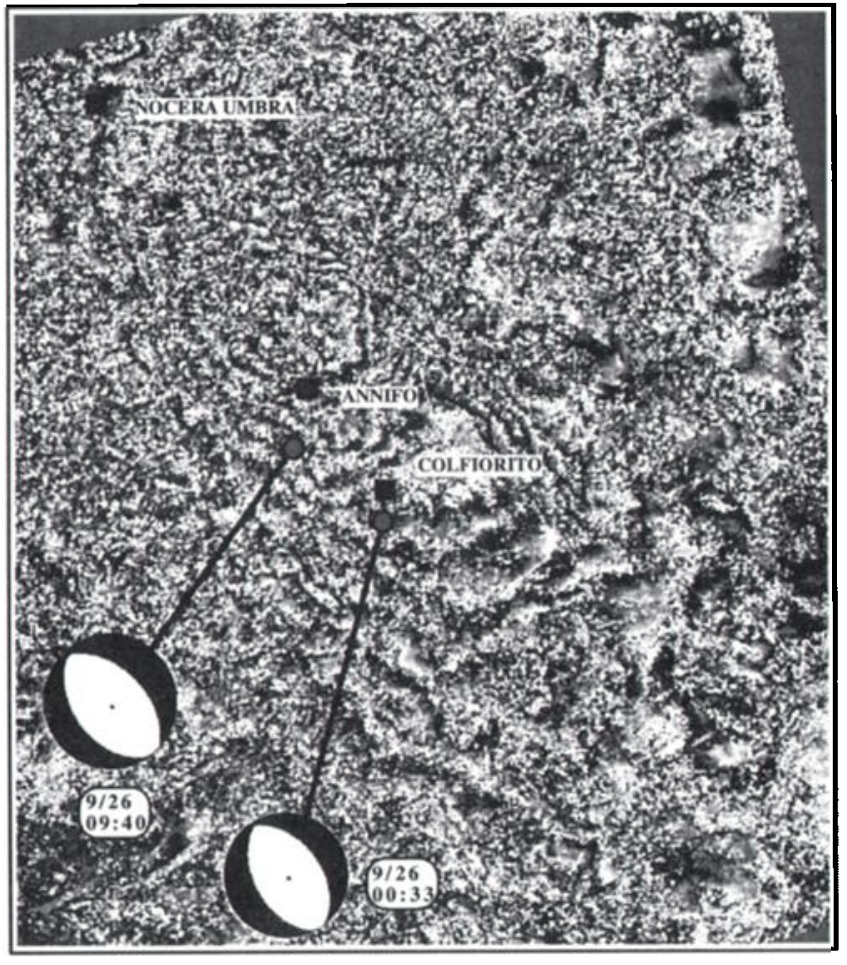

Figure 1. $\quad \stackrel{-\pi}{S} \stackrel{1}{\mathbf{0}} \stackrel{+}{+\pi}$ Colfiorito area showing the total surface displacement occurred between September 7 and October 12, 1997. Each fringe represents a full phase cycle $(+\pi-\pi)$ caused by a displacement increment of $-28 \mathrm{~mm}$ in the slant range; the direction of the increment is from the outermost fringe inward. Also shown are the epicentral location of the two September, 26, shocks and the CMT focal mechanisms (after Ekström et al., [1998]). To better retain the details of the fringe pattern, the image is not geocoded (SAR geometry). The small residual fringes visible towards the extreme right of the image are presumably related to propagation delays due to tropospheric turbulence.

about $14 \mathrm{~km} \mathrm{N-S}$ and $10 \mathrm{~km} \mathrm{W-E}$. Given the limited temporal baseline ( 35 days), it likely represents the total coseismic displacement of both the 00:33 and 9:40 GMT, September 26, main-shocks. The displacement increases constantly towards the Annifo plain, where a maximum of $252 \mathrm{~mm}$ (nine fringes) of surface displacement is found (Figure 2).

\section{The GPS data}

Shortly after the main shocks we re-surveyed a subset of the Italian Istituto Geografico Militare, IGM95 GPS network [Surace et al., 1997] located around the epicentral zone [Anzidei et al., 1998]. The GPS data were processed using the Bernese software version 4.0 [Rothacher et al., 1996]. We obtained 3-D coordinates with a mean accuracy of $14 \mathrm{~mm}$ and $25 \mathrm{~mm}$ in the horizontal and vertical components respectively $(95 \%$ confidence) As reference coordinates we used those

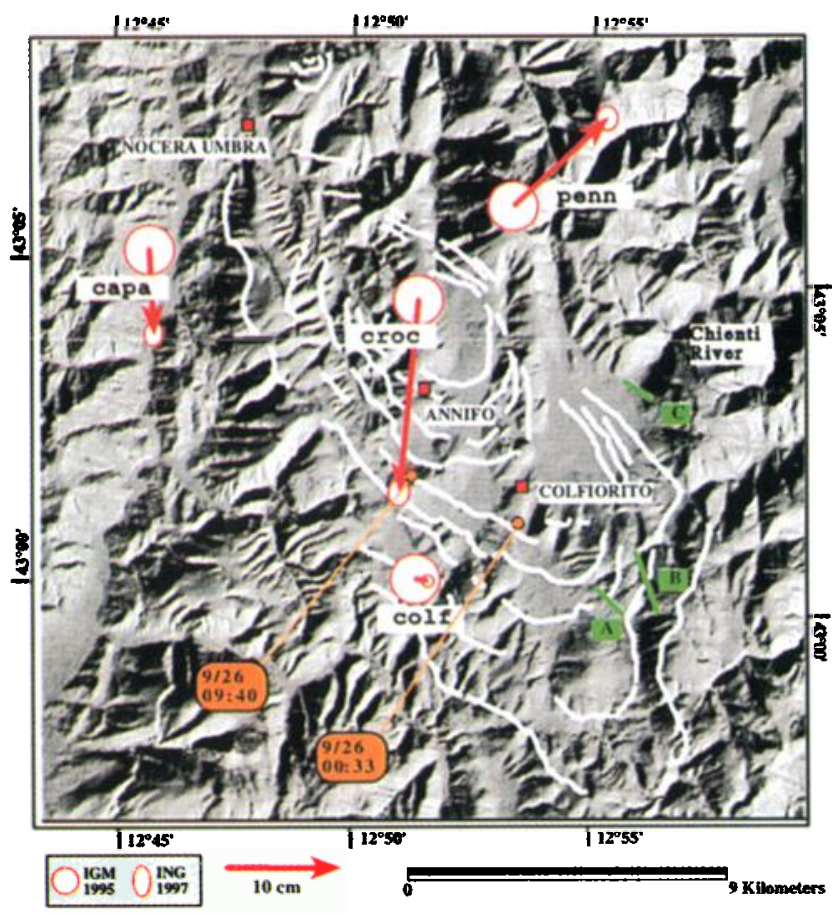

Figure 2. Geocoded displacement contours retrieved from the interferogram in figure 1. Each contour line represents a displacement increment of $-28 \mathrm{~mm}$ in the slant range. GPS stations (in lowercase), planar displacement vectors (red arrows), and 95\% confidence error ellipses for the 1995 and 1997 epochs (see Table 1), are shown. A and B are the traces of the bedrock fault plane reactivations (after Basilz et al., [1998]). C is the location of the scarp damming the outlet of the Colfiorito basin.

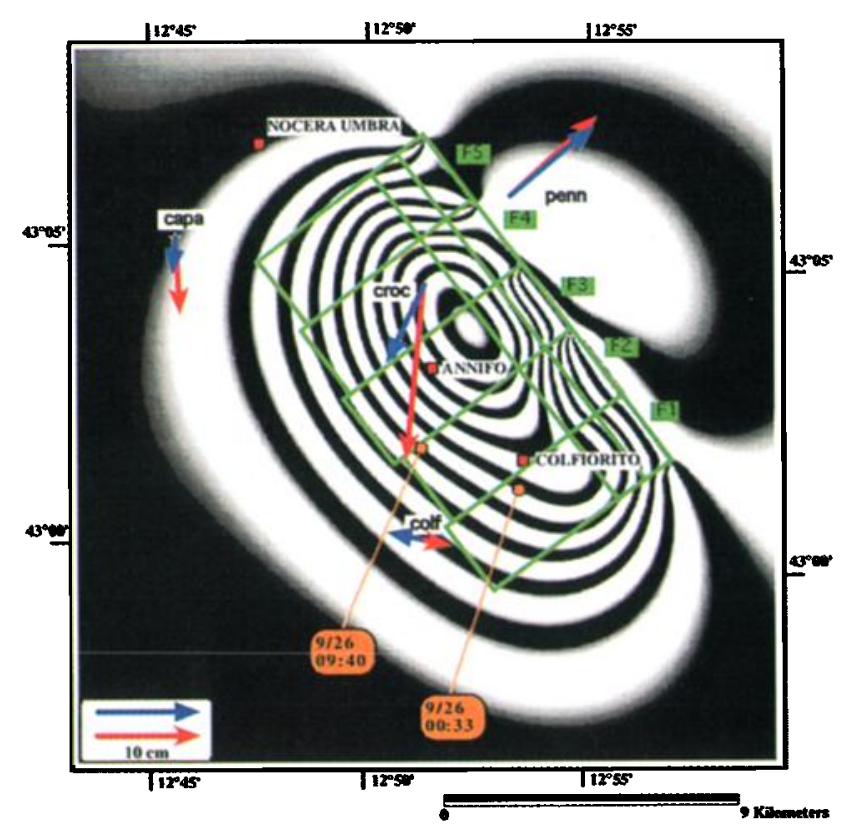

Figure 3. Synthetic interferogram and surface projection of the fault model. The paramerers for the 15 fault patches are reported in Table 2. Displacement vectors and GPS stations as in figure 2. Modeled horizontal displacement vectors at the GPS stations are shown as blue arrows. 
Table 1. Observed and calculated GPS displacements

\begin{tabular}{cccccccc}
\hline \multirow{2}{*}{$\begin{array}{c}\text { GPS } \\
\text { point }\end{array}$} & Obs. GPS & Calc. GPS & Obs. SAR & \multicolumn{2}{c}{ Obs. GPS horizontal } & \multicolumn{2}{c}{ Model } \\
\cline { 7 - 8 } & vertical & slant range & displacement & $\mathrm{dE}$ & $\mathrm{dN}$ & $\mathrm{dE}$ & $\mathrm{dN}$ \\
\hline COLF & -69 & -58.8 & -56 & 12 & -2 & -13 & 5 \\
PENN & -39 & -9.2 & 0 & 80 & 77 & 30 & 25 \\
CAPA & 1 & 7.9 & 0 & 10 & -57 & 0 & -10 \\
CROC & -247 & -224.7 & -252 & -19 & -139 & 2 & -30 \\
\hline
\end{tabular}

All values are in $\mathrm{mm}$.

computed by IGMI at the 1995 epoch, with a mean accuracy of $22 \mathrm{~mm}$ in the horizontal and $35 \mathrm{~mm}$ in the vertical components respectively ( $95 \%$ confidence). To compare IGMI and our 1997 coordinates we applied a 7-parameter transformation [Anzidei et al., 1998]. Eventually, only Collecroce (CROC), Pennino (PENN), Colfiorito (COLF) and Capannacce (CAPA) detected a significant displacement (Figure 2).

When projected onto the SAR line of sight the GPS displacements agree well with the SAR displacements (Table 1). The large horizontal values at PENN, CROC and CAPA are nearly parallel to the ERS orbit and contribute marginally to the GPS displacement in the slant range direction.

\section{Fault modeling and discussion}

We modeled the data using an inversion program [Brole et al., 1986] based on a least square minimisation algorithm [Tarantola et al., 1982] and representing the source as a rectangular fault in a uniform elastic half-space, using the Okada (1985) formulation. We used in the model 258 values of range change (one point every $0.5 \mathrm{~km}$ along each fringe) and the 4 GPS horizontal displacement values (Table 1), since the vertical GPS components are in good agreement with the fringe displacements. Based on the hypocentral distribution for the entire sequence [Amato et al., 1998] and on the opposite directions of the rupture propagations

Table 2. Modeling results: slip for each patch and total seismic moments

\begin{tabular}{cccccc}
\hline \multirow{2}{*}{ Patch layer } & \multicolumn{3}{c}{ Event 09:40 } & \multicolumn{2}{c}{ Event 00:33 } \\
\cline { 2 - 6 } (depth range) & F5 & F4 & F3 & F2 & F1 \\
\hline Upper $(0-1 \mathrm{~km})$ & 13 & 24 & 16 & 5 & 6 \\
Medium $(1-2 \mathrm{~km})$ & 12 & 29 & 29 & 5 & 19 \\
Lower $(>2 \mathrm{~km})^{\mathrm{a}}$ & 41 & 72 & 69 & 30 & 47 \\
\hline
\end{tabular}

\begin{tabular}{ccc} 
Seismic moment & & \\
Model & $105.2 \times 10^{16} \mathrm{Nm}$ & $42.5 \times 10^{16} \mathrm{Nm}$ \\
CMT Moment & $120 \times 10^{16} \mathrm{Nm}$ & $40 \times 10^{16} \mathrm{Nm}$ \\
\hline
\end{tabular}

Slip is in cm, CMT moments from Ekström et al.,1998.

${ }^{a}$ Depth of fault plane variable between 6.5 and $7 \mathrm{~km}$, see fig. 3 of the two mainshocks (A. Pino et al., Rupture directivity of the major shocks in the 1997 Umbria-Marche sequence from regional broadband waveforms, submitted to Geophysical Research Letters, 1998) we assume that the two faults belong to the same tectonic structure. In order to determine the slip distribution during the earthquake, we joined the two fault planes in a single plane $12.5 \mathrm{~km}$ long, with dip $45^{\circ}$, strike $144^{\circ}$, rake $270^{\circ}$ [Ekström et al., 1998]. We divided the fault in 15 patches (Figure 3), allowing for slip on the fault at depths between 7 and $1 \mathrm{~km}$ (Table 2). The final r.m.s. residual is $16 \mathrm{~mm}$, well below the value of one fringe ( 28 $\mathrm{mm})$. It appears that, for the 09:40 event, a better fit of the horizontal GPS displacements requires considerable slip at shallow depths. In fact, giving a weight 0 to the GPS data results in a reduction of the maximum slip from $24 \mathrm{~cm}$ (with weight=1, Table 2) to $10 \mathrm{~cm}$ for the upper F4 patch. The total seismic moment (we used a rigidity value of $3 \times 10^{10} \mathrm{Nm}^{-2}$ ) is close to the CMT moment of Ekström et al. [1998] (Table 2).

For the 09:40 event, Hunstad et al., (in their paper: Modeling coseismic displacements during the 1997 Umbria-Marche earthquake, submitted to Geophysical Journal International, 1998), performing a forward modeling of the same GPS data, found maximum slips and top-of-fault depths in agreement with our results $(65 \mathrm{~cm}$ and $0.3 \mathrm{~km})$. Their estimates for the 00:33 event are sligthly different $(36 \mathrm{~cm}$ and $3 \mathrm{~km})$, but in their model this event is well constrained by only one GPS data, at COLF. The previously cited broadband waveform analysis by Pino et al., suggests maximum slips of $52 \mathrm{~cm}$ and $65 \mathrm{~cm}$ for the 00:33 and 09:40 events respectively. These authors (and Olvviern et al., [1998]) also suggest that the 09:40 event is composed of two subevents, about 4 $\mathrm{s}$ apart, the second being located about $12 \mathrm{~km}$ North of the hypocenter. The three small semi- circular fringes in the upper part of figure 1 are located at $12 \mathrm{~km}$ from the 09:40 epicentre and in principle they could be related to the second subevent, but there is no other clue to this interpretation.

As already noted by [Peltzer et al., 1995] for the 1993 Eureka Valley (California) sequence, some of the fringe complexities (merging, interrupted, and/or displaced fringes) in figure 1 could represent local surface deformation due to shallow, moderate aftershocks $[\mathrm{Am}$ ato et al., 1998], not considered in our model. In the 
area SE of Colfiorito, Basili et al. [1998] describe up to 5 $\mathrm{cm}$ displacement along bedrock fault planes for lengths of 1-2 km which can be seen in figure $2(\mathrm{~A}, \mathrm{~B})$. Other evidences of surface displacement mapped by Basili et al. [1998] and Cinti et al. [1998] are too local (max length $300 \mathrm{~m}$, i.e. $7-8$ pixels in figure 1) to be recognized in the interferogram.

Finally, we remark a certain similarity between the displacement pattern and the general topographic setting of the area, which includes the plains of Colfiorito and Annifo (Figure 2). This and other evidences, such as the tectonic scarp (C in figure 2) blocking the drainage from the Colfiorito basin towards the NE [Cello et al., 1997], suggest that the presence of a topographic low in this area may be a direct consequence of repeated seismic deformation occurred during the Upper Quaternary.

\subsection{Conclusions}

We applied ERS SAR interferometry to the 1997 Umbria-Marche epicentral area. We retrieved the surface displacement field for the 26 September mainshocks and measured a maximum of $252 \mathrm{~mm}$ of range displacement in the interferogram. We applied an elastic dislocation model to the DInSAR and GPS observations, obtaining a rather good fit. The maximum depth of the faults is well constrained and stable at $6.5-7 \mathrm{~km}$ and the pattern of slip distribution shows that for the 09:40 event most of the energy was released from an area of $5 \times 7 \mathrm{~km}$ in the southeastern part of the fault (Table 2).

The large slip values at shallow depths $(0-1 \mathrm{~km})$ in our model (Figure 3) for the 09:40 event do not correspond to surface faulting of comparable size, even if a high displacement gradient (Figure 1 and 3 ) is present close to the top of the fault. This suggests that the rupture stopped very close to the surface, as also proposed by Cinti et al. [1998]. The SAR and GPS observations and our modeling results are in good agreement with the independent results from geological and seismological data.

Acknowledgments. Thanks to ESA, ASI and Telespazio s.p.a. for providing the ERS images, the Italian Civil Protection for financial support and the IGMI for collaboration. Part of the research has been funded by the Italian Space Agency, contract No. RS 96-87 and Telespazio.

\section{References}

Amato, A., R. Azzara, C. Chiarabba, G.B. Cimini, M. Cocco, M. Di Bona, L. Margheriti, S. Mazza, F. Mele, G. Selvaggi, A. Basili, E. Boschi, F. Courboulex, A. De- schamps, S. Gaffet, G. Bittarelli, L. Chiaraluce, D. Piccinini, M. Ripepe, The Colfiorito, Umbria-Marche earthquake sequence in central Italy (Sept.-Nov., 1997): a first look to mainshocks and aftershocks, Geophys.Res.Lett., 25, 2861-2864, 1998.

Anzidei M., P. Baldi, A. Galvani, I. Hunstad, A. Pesci, Coseismic displacement of the 26 September 1997, UmbriaMarche (Italy) earthquakes detected by GPS, Annali di Geofisica, in press, 1998.

Basili, R., V. Bosi, F. Galadini, P. Galli, M. Meghraoui M., P. Messina, M. Moro, and A. Sposato, The Colfiorito earthquake sequence of September-October 1998: surface breaks and seismotectonic implications for the Central Apennines (Italy), J. Earthquake Eng., 2, 1-12, 1998

Briole, P., G. De Natale, R. Gaulon, F. Pingue and R. Scarpa, Inversion of geodetic data and seismicity associated with the Friuli earthquake sequence (1976-1977), Annales Geophysicae, 4, 481-492, 1986.

Cello, G., S. Mazzoli, E. Tondi, and E. Turco, Active tectonics in the Central Apennines and possible implication for seismic hazard analysis in peninsular Italy, Tectonophysıcs, 272, 43-60, 1997.

Cinti, F.R., L. Cucci, F. Marra, P. Montone, The 1997 Umbria-Marche (Italy) sequence: relationship between ground deformation and seismogenic structure, Geophys.Res.Lett., in press, 1998.

Ekström, E., A. Morelli, E. Boschi, and A.M. Dziewonski, Moment tensor analysis of the Central Italy earthquake sequence of September-October 1997, Geophys.Res.Lett., 25, 1971-1974, 1998.

Massonnet, D., Rossi M., Carmona C., Adragna F., Peltzer G., Feigl K., Rabaute T., The displacement field of the Landers earthquake mapped by radar interferometry, $\mathrm{Na}$ ture, 364, 138-142, 1993.

Okada, Y., Surface deformations due to shear and tensile faults in a half-space, Bull. Seism. Soc. Am., 75, 11351154,1985

Olivieri, M., and G. Ekström: Rupture Depths of Recent Earthquakes in Central Italy, Bull. Sersm. Soc. Am., submitted 1998.

Peltzer G., and P. Rosen, Surface displacement of the 17 May 1993 Eureka Valley, California, earthquake observed by SAR Interferometry, Scrence, 268, 1333- 1336, 1995.

Rothacher, M., and Mervart L., Bernese GPS software version 4.0, Astronomical Institute University of Berne, 1996.

Surace, L., La nuova rete geodetica nazionale IGM95: risultati e prospettive di utilizzazione, Bollettino di Geodesia e Sczenze Affini, 3, 357-377, 1997.

Tarantola, A., and Valette B., Generalized nonlinear inverse problem solved using the least squares criterion, Rev. Geophys. Space Phys., 20, 219-232, 1982.

S. Stramondo, Instituto Nazionale di Geofisica, Via I Vigna Murata. 605, Roma, Itay (e-mail: stramon(anettuno.igrm. it)

(Received April 21, 1998; revised December 14, 1998; accepted January 8,1999 .) 